\title{
Combining Transparency and Accountability Perception with Ranking Simulation (The case of Indonesian Police Academy Recruitment in 2012)
}

\section{Nyoman Sudama}

Doctoral Program of Indonesian Police Science College, nsdama@ gmail.com

Citation:

Sudama, I. Nyoman, Combining Transparency and Accountability Perception with Ranking Simulation, (The case of Indonesian Police Academy Recruitment in 2012), Management Technology and Security International Journal, page 89-103

Received on 6 June 2020, Accepted on 09 July 2020, Published on 1 August 2020

\begin{abstract}
This paper examines transparency and accountability perception among prospective police cadets of Indonesian Police Academy (Akpol) recruitment in 2012. The examination was based on survey data of 33 police candidates who passed the final test and 448 police candidates who have to have Akpol's final test at Sukabumi, Bandung, in 2012. The survey also collects information from the Central Java Police officers for further information on the recruitment process. The survey results confirm that the recruitment process was transparent and accountable that represents the satisfaction of police candidates. However, some questions emerge in terms of the ranking process that might need more explanation since the ranking and cut off point for all candidates have never been publicly revealed. This paper simulates a simple additive weighting method that could be an alternative choice for constructing cut off points as well as a rank system in the police recruitment process.
\end{abstract}

Keywords: accountability, transparency, SAW, recruitment, Akpol

\section{Introduction}

Accountability and transparency are relevant issues in any kind of government body including national police in every country. They are a means of trust that people give to their government institutions to govern the country in any kind of area including national law enforcement and security. When there are accountability and transparency, there is a trust to work together as a community and nation to achieve a better quality of life.

In the decentralisation and democratization era, Indonesia encounters complex problems that require a clear solution from the government body including police institutions. People become more aware of their right to speak and demand an explanation about any cases of people-state relationships. Particularly the law enforcement process and human rights become hot issues to be treated in transparent and accountable manner.

One of the most prominent segments that people inquiry is a police recruitment process to enter Akpol as the top government funding police school. This is not just in the people's interest to know about the process but also the reputation of the recruitment has been downgraded by improper issues spread through mass media. It includes the collusion and nepotism 
practice among some of the steps from regional until the national level.

The purpose of this study is to know how the police candidates perceive their recruitment and whether they are satisfied with the selection processes. It is imperative to know the opinion from the ones who actively involves in the process as they feel how the selection is carried out from the beginning until the end. This information is highly important for Akpol and Indonesian National Police (Polri) to understand the weakness and the strength of the police recruitment process that has been done as part of national human resources development responsibility.

The survey for the study was conducted in 2012 Akpol's admission test by asking 33 police candidates and 448 police cadets who experience the recruitment process from regional until the national level. For more accurate information, the study also conducts a deep interview with key persons of Central Java police officers.

The results show that most of the respondent reveals that Akpol's recruitment process is accountable and transparent. Most of the respondents satisfy with the selection and feel that the process was fair enough and treat every candidate without any kind of discrimination. However, from a deep interview with some police candidates and people who have different experiences out of the sample, there is the ranking system that mostly unknown and leave some unexplainable part of the whole hiring procedures. People can see the written, interview, and health-related tests but cannot say anything about the cut-off point in the ranking system.

Base on this finding, this paper tries to propose the Simple Additive Weighting (SAW) method as an alternative step to complement the Akpol hiring procedure.
The method is understandable and fulfills the fairness of its scientific methodology and easy to implement with any kind of spreadsheet platform. A simulation of how the method works will be explained with real criteria adopted from OSCE (2008) and Trojanovicz and Bucqueroux (1998). As an alternative method, SAW could be used to solve a specific problem in case the current methodology fails to be implemented like a similar candidate with the same point.

\section{LITERATURE REVIEW}

\subsection{Good governance, accountability, and transparency}

Good governance, accountability, and transparency attract much attention from policymakers at regional, national, and global levels since an increase in awareness of human rights and people's expectations on government performance as a public services provider. The advancement of democracy and the regional autonomy in some parts of the world demand more attention toward law enforcement, human right, democracy, and transparency. This, in turn, leads to the hope that the government and its institutional bodies including police institutions can function as the law of the rules to gain trust from the whole country for harmonies relation between people and the state.

Indonesia State Administration Agency (LAN) explains that governance is the process of state administration and power in providing public goods and services (LAN, 2001). By referring to United Nation Development Programme (UNDP), LAN (2001) determines that there are nine aspects of good governance which are participation, rule of law, transparency, responsiveness, consensus orientation, equity, effectiveness and efficiency, accountability, and strategic vision. 
Sheng (2009) in United Nations Economic and Social Commission for Asia and the Pacific (UNESCAP) publication mentioned that there are eight characteristics of governance such as participatory, consensus-oriented, accountable, transparent, responsive, effective, and efficient, equitable and inclusive and follows the rule of law. Among those characteristics, two of them are the main concern of this paper that is accountability and transparency. Despite both of them are the highest concern of the Akpol recruitment process, these characteristics are the most prominent aspect that people complaining about in the Indonesian National Police Institution as part of the democratization era.

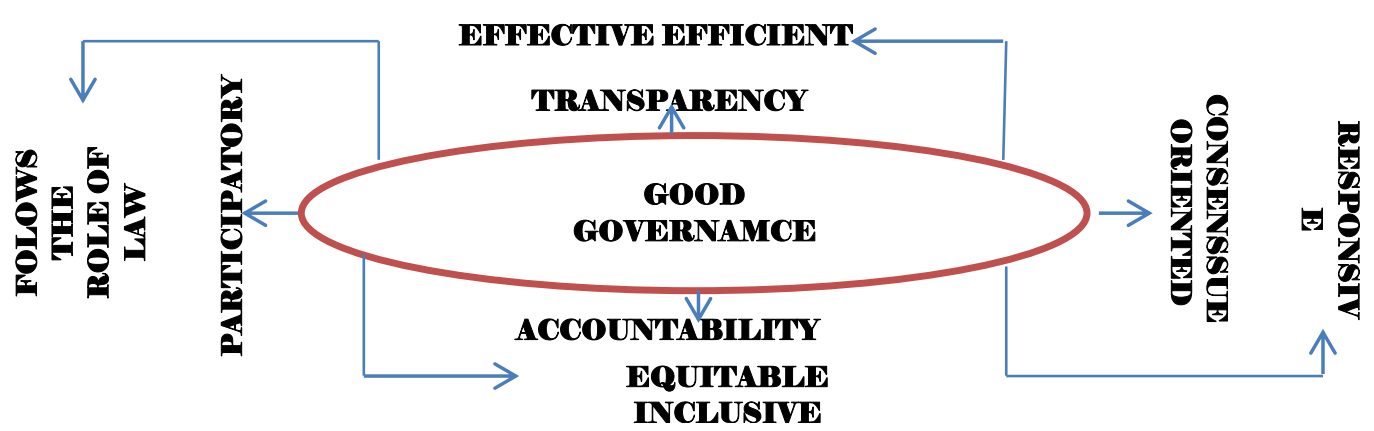

Figure 1. UNESCAP Good Governance Characteristics

UNESCAP (Sheng, 2009) defines transparency as information available in any kind of recruitment process involving easy to access, up to date, reliable, valid, and informative. Akpol has to provide people with the current recruitment procedures in case there are updated and changed due to practical improvements. Any changes and new items that have been added to the procedures every year have to be clearly defined and declared to the public. This also means that the way that information about the recruitment process spreads and announces is an important part of the whole process. The purpose is that the recruitment procedures can be easily accessible and understandable for all police cadet applicants.

Sheng (2009) and Walsh and Conway (2011) argue that accountability and good governance are similar and having part of each other. This paper defined accountability as the responsibility performance of specific individual tasks or organization functions. UNESCAP (Sheng, 2009) argues that accountability cannot be separated from two other good government characteristics that are transparency and the role of law. Therefore in this paper, like in Walsh and Conway (2011), the use of accountability might be a complement of good governance and when the terms mentioned in the same statement could mean the same term for similar purposes. That is why in this study the questioners only ask the police accountability to the respondent instead of explaining the term good governance since police accountability is more popular than the good governance itself.

\subsection{Selection Process}

Police recruitment is a crucial part of the future of the Indonesian police. In police life cycles the recruitment means to make sure the best human resources will serve the nation with its full potential. This is not just in the academic terms but also in social, political, psychological, cultural background, and attitude toward public 
services. As part of human resources development, police recruitment will determine the regeneration process of Polri and its ability to maintain accountability service to the nation and the people.

There are many kinds of police selection processes among the country in the world which depend upon the background of the country. However most of them have something in common in which the selection process follows the steps such as (1) application and eligibility; (2) application assessment; (3) writing exam; (4) physical examination; (5) medical examination; (6) psychological examination; (7) background screening and (8) final committee decision. Some countries also incorporate polygraph (Pynes and Bernardin, 1992) or educationemployment-psychometric historical interview (PEAC, 1998). Another procedure that is commonly adopted by the police

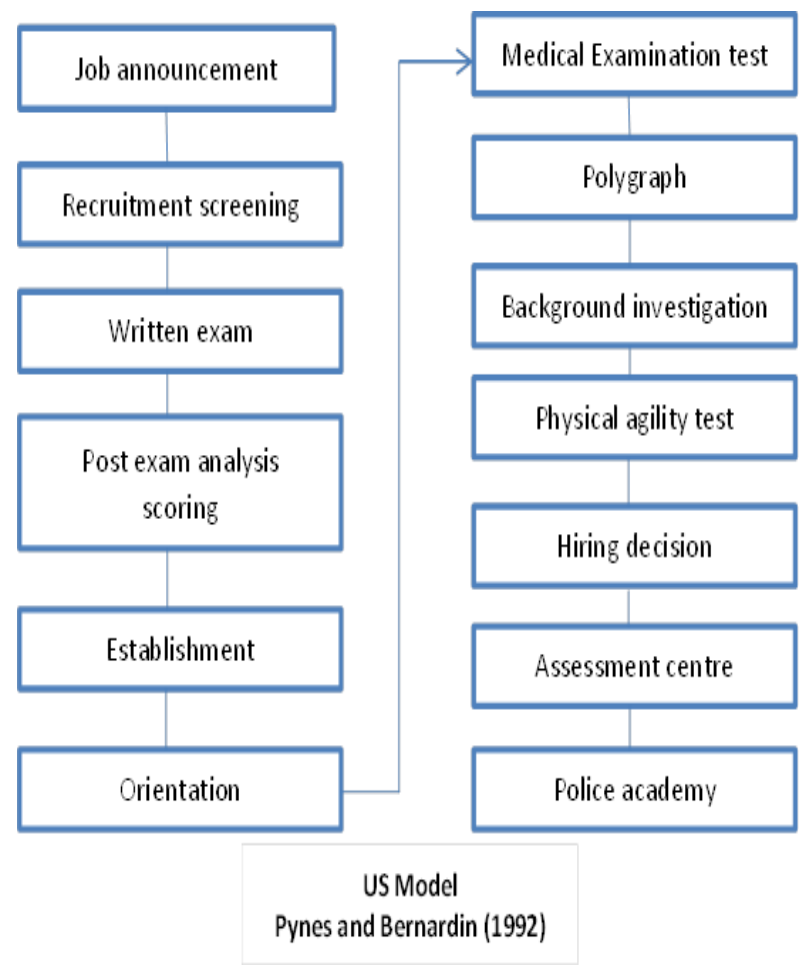

recruitment process is a cut-off ranking system in which the amount of applicants accepted is based on their rank against other applicants.

In general, there are nine steps of selection in the Akpol recruitment process involving: (1) administration, (2) writing examination, (3) intelligence selection, (4) interview. (5) practical-orientation examination, (6) physical examination, (7) special talent-ability test, (8) psychological test, and (9) medical test. These steps have fulfilled the requirement steps of police recruitment around the world. As a comparison, there are two diagrams below which show step by step recruitment tests in Australia and the United States that have been explained in PEAC (1998) and Pynes and Bernardin (1992).

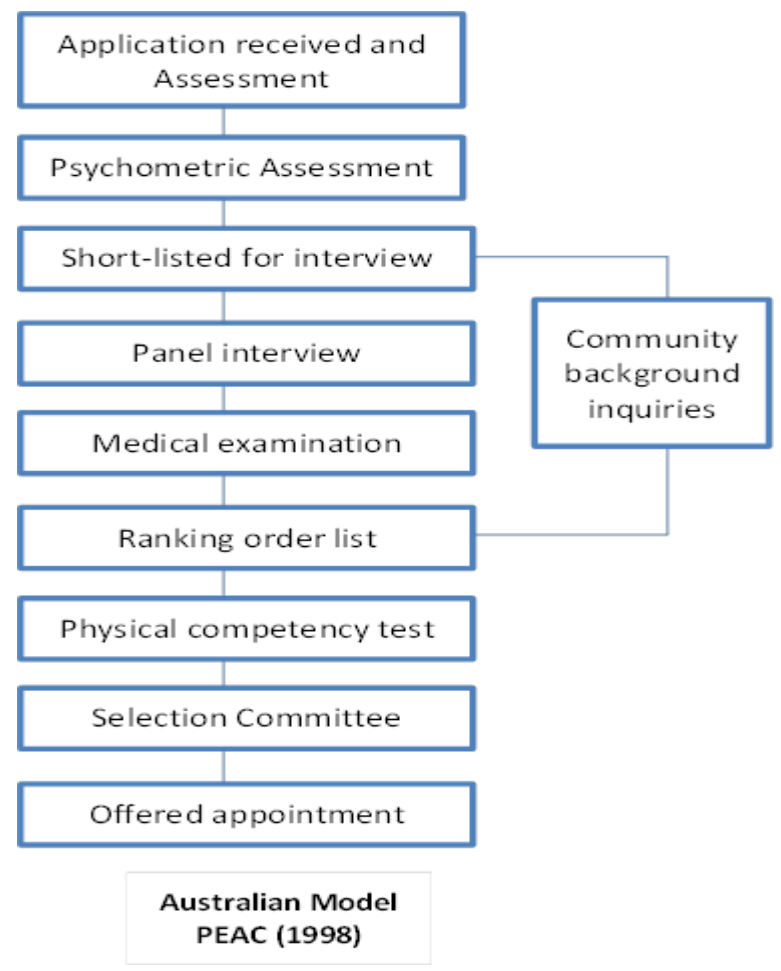

Figure 2. Comparing United State and Australia as reference for Akpol recruitment development model 


\section{METHOD}

This study is qualitative in nature but some quantitative measurement and statistical tests also involved in simulating the SAW approach. The data was collected among 33 police candidates who passed the overall test and secures their status as Akpol student in 2012. This 33 student was asked several questions about their experiences in recruitment tests in relation to fairness, transparency, and accountability of the overall steps.

Another data was collected from 448 police cadets who involve in the Akpol recruitment process for 2012 intake. Similar to the 33 respondents, the question was about the accountability and transparency of the hiring activities. To gain more insight and as comparable data to support the analysis, eight key persons of Central Java Police officers were interviewed for more information that might be missed from the survey. The data for the SAW method was also given to this person and some Akpol recruitment staff for SAW simulation estimation.

\section{RESULT}

\subsection{Descriptive analysis}

As this research belongs to the case study with survey data, the response rate will be very critical to be discussed before analyzing further or processing the data for analysis. This survey can be classified as high respond survey since the rate of filling questionnaire is more than 90 percent. Among the three kinds of data, the first data response rate is 96.96 percent. Almost all respondent answer the question and give a comment to the open questions Among 33 respondent of the first kind of data, 28 people fill the questioner with additional comment, 4 respondents did not give their opinion in term of individual assessment but they set out some comments in the open questions and only one respondent did not a response to either multiple choices or open questions.

The response rate can affect the overall research since it relates to the reliability and validity of the research. The survey that has very low response rate can be said to have a high level of nonresponse bias (Finchan, 2008). The survey that has only a 10 percent response rate meaning the research supper from 90 percent nonresponse bias, similarly, a survey with a 50 percent response rate indicates 50 percent nonresponse bias which is sometimes becomes overlooked unresolved problems. There are some treatments for this weakness which depend on the sampling technique that one employs. However, besides any kind of extrapolation or interpolation, the ideal response rate to secure the validity and reliability of the survey is 80 percent (Finchan, 2008).

For the second and third data of this survey, the response rate is 100 percent. There is an advantage to do this research in Akpol's selection process since the police candidates and police cadets mostly have a better response in helping each other or well understanding to involve in something that might give a possibility for greater progress or good for other people. This kind of the point of view is common among the ones who interest to work in the area of public services otherwise they have no sense of ministration and better not involve in any kind of public service employment recruitment. 


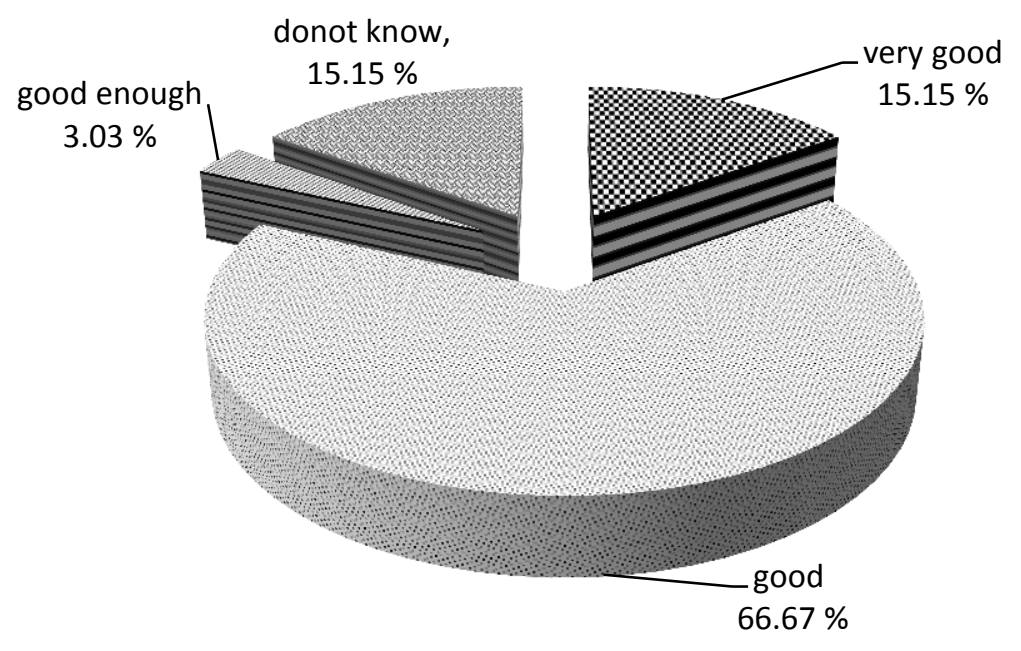

Figure 3. Respondent opinion from the first data (very good, good, good enough and do not know)

Having have no problem with nonresponse bias, the survey results show that most respondents agree that Akpol recruitment process was conducted in a fair and good manner (66.67 percent), 15.15 percent respondent reveals that the process was excellent and 3.03 percent said that the process was good enough (Figure 3). There is 15.15 percent of the respondent in the survey have no comment on the process and choose to not give their opinion. This last number could be that they feel that expressing their opinion will affect their position to be police candidates and could be also a fear that their opinion could be used against them. This is common to the new nominees in the police academy that it is better to be quiet otherwise you will have more problems as a junior. However, the inferior mute culture is not a good signal to promote a democratic society in which expressing opinion is highly valued for better communities.

Another result from the first data can be seen in Figure 4. The figure describes that 36.36 percent of police candidates agree that the recruitment process was fair and transparent, 24.24 percent mentioned that the process needs improvement, and 6 percent belong to others classifications. The figure also reveals dubious results since there is more than 30 percent of the respondent have no comment. Whether this related to the same reason as mentioned previously that as a new police candidate, it will be saved to be calm and nonresponse about the recruitment process to avoid unprecedented troubles or this is caused by the respondent's different point of view that need further intensive research.

There is also a relatively high percentage of respondent who argues that the recruitment process needs to be improved in the future. The 33.3 percent of no comment could also mean that they have something to say but it is better to secure their position as police candidates by not giving an argument. The 6 percent that belongs to other indicates an interesting experience in which respondent mentioned that the process needs to be more relax and need more moderate situation among the judge or committee so that the cadets or police candidates have less anxiety or pressure in the process. The advantageous circumstances will help the police cadets to show their real potential during the test. Psychologically, the unfavourable situation during the test could make the candidates under pressure thus less likely to help their ability to perform better. 
Another comment argues that it is beneficial to give more weight to the academic tests compare to other kind of tests since academic performance is useful for the future of Indonesian police. This stance might be a good input for future police human development but have to be taken under very careful consideration. Supporting views on it may be base on the fact that different kinds of stipulations on the balance of professional police and the dynamic of the future of policing that need people who understand the analysis of data, doing research, and operate better technologies to

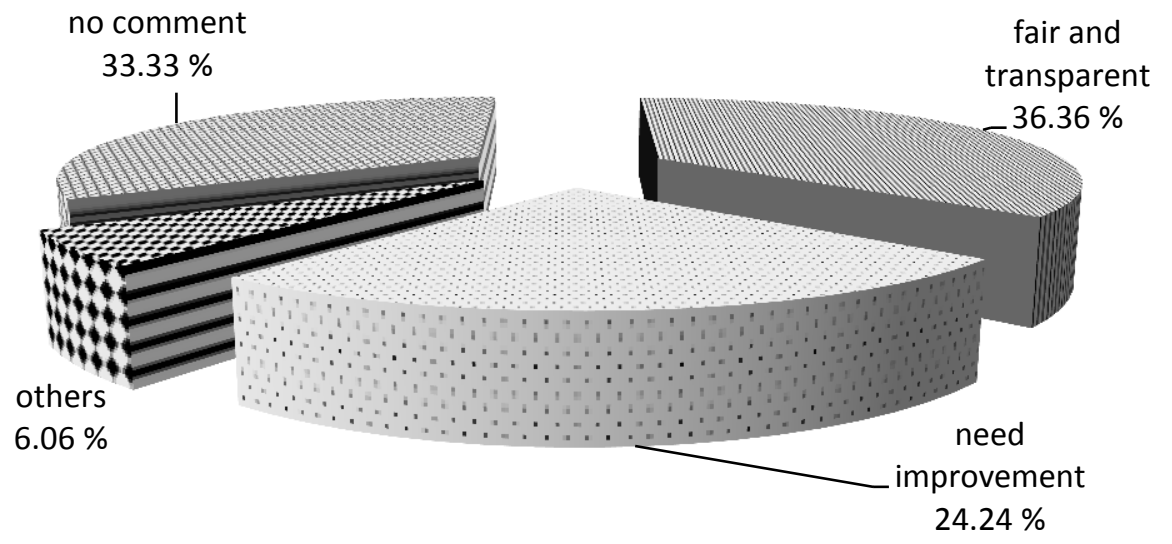

Figure 4. Respondent opinion from the first data (fair and transparent, need improvement, others and no comments)

Figure 5 is the results of the second data. The graph shows that most of the police cadets satisfied with the recruitment process (46.40 percent). This result underpins the finding of the Indonesian Police Headquarter (Mabes Polri) survey in which found that recruitment of the police cadet in 2012 satisfied most of the applicants (Mabes Polri, 2012). If we compare this result to the support police specific task. Giving different weights in different criteria should be appraised in relation to the urging of particular skill in Indonesian police and to support long term planning in human resources development. Physical assessment is important but academic and special skill also needs to be used as a complement in the human resources development. The ultimate goal is to make sure that the police department chooses the best people in the right position to support better the police for Indonesia. 


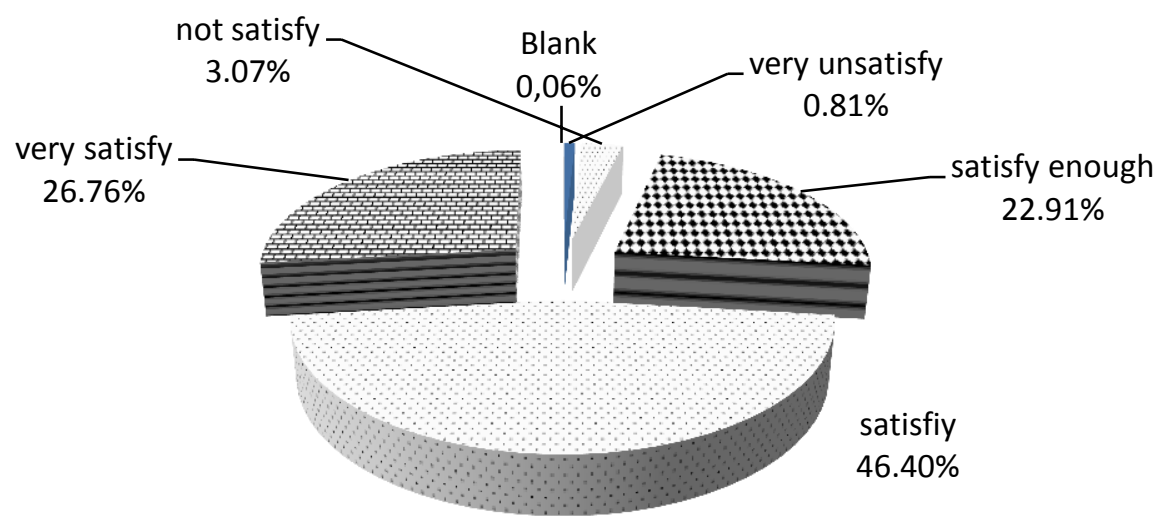

Figure 5. Respondent opinion from the second data

There are some important results from depth interviews with the Central Java police officers that involve in the recruitment processes. The first is in a similar direction with the first and second data that the respondents agree that Akpol's selection test fulfill the accountability and transparency requirements. There are no collusion and nepotism found in the selection steps and all respondents acknowledge that there is no fee to be accepted in any kind of form to ease the process for particular police cadets or candidates. Corruption, collusion, and nepotism come to the fore of the test as under table money at some point in time emerges as an obscure issue that needs to be brought to light. The deep interviews also reveal that the higher level of the test (national test) was more difficult than a regional one. This is a common practice and the convention shows the reliability of the steps since the higher of the level the small number of people are needed and the tougher the tests are.

The last predicament that was found in the 2012 Akpol recruitment that the police cadets and police officer concern about was the different format of announcement between the website and hard copy (paperbased). The participant asked about the grade that never been announced on the website. However, in the paper-based list, the ranking was clearly disclosed. This could be a good input for the future recruitment process to put both ranking and grade on the Polri's or Akpol's website thus people can access the information directly from their mobile phone without coming to the police station (Polres or Polda). Some participants also make inquiries about how the police institutions decide the grading and ranking, in particular, any hiring processes. They request the possibility that the final ranking system to be explained on the website to make the applicants understand why someone cannot pass the process or why some candidates have a low grade and therefore low rank among others.

Overall, the convergence of the results of this research with the consumer survey managed by Mabes Polri indicates the promising future for human resource development in Indonesian police institutions. Both proclaim that recruitments processes have been done fairly, with equal treatment, no corruption, collusion, or nepotism so the perspective of accountability and transparency has been attained. However, some process needs to be considered for better results. Firstly, supervision from the Polri headquarters needs to be improved to the scrutiny of any kind of misconduct in the recruitment 
process at the regional level. Secondly, regular evaluation and updates of the process, equipment, and human resources involved in the test and the system itself will help to gain better outcomes. Thirdly, a system that can do self-check to any kind of illegal recruitment process might assist to avoid undercover behaviors that missing from regular supervision. Lastly, there is an

\subsection{SAW approach}

Simple Additive Weighting (SAW) method is a method of conducting ranking in a recruitment test which involves some kind of criteria. The method is prominent because it suggests a weighting system that fairly applies to the criteria and against the performance of the candidates. The method also can be applied in simple platform like data processing or statistical package program. Those who interest to modify the technique into a permanent package data processing are highly recommended since the method support any programming environments. This makes SAW excavates the likelihood to make it as the main step or as a complement to another decision making in any kind of area like business, investment choices, or human resources.

The method involves three main steps that are constructing a pairwise comparison matrix, develop normalization matrix and analysis of consistency. There is no room for manipulating the results if the programs have been fixed design in particular form so the only needed is the input data. This is the idea to use the method in the institution like unclear explanation to the police candidates about the ranking system and how to decide the cut-off point of deciding who pass or not pass the selection process. For this last obstruction, this paper proposes a simple additive weighting method in which as an additive method, can function as a supplementary step for overall Akpol recruitment processes.

Akpol to make this method as an accompaniment in case some people make an inquiry about the hiring results or there is similar ranking come up by using the conventional ranking system.

Step 1: developing a pair wise comparison matrix

Ten criteria are chosen from OSCE (2008) which adopted from Trojanovicz/Bucqueroux (1998) as a basis to build police-public partnership. They are $\mathrm{C} 1$ (proactivity), $\mathrm{C} 2$ (natural and social respond), C3 (communication), C4 (problem solving), C5 (sensitivity), C6 (priority), C7 (negotiation and organisation), C8 (neutrality), C9 (respect) and C10 (political alliance).

We will compare the degree of the importance of the criteria by using the explanation that $1=$ equally important, $2=$ modest important, $3=$ medium important, 4 $=$ medium-plus important, $5=$ significant important, $6=$ very significant important, 7 $=$ strong important, $8=$ very important, and $9=$ extraordinary important. The same scale is applied to the less important criteria. 
Table 1 Example of primary questioner and pairwise comparison matrix degree 3

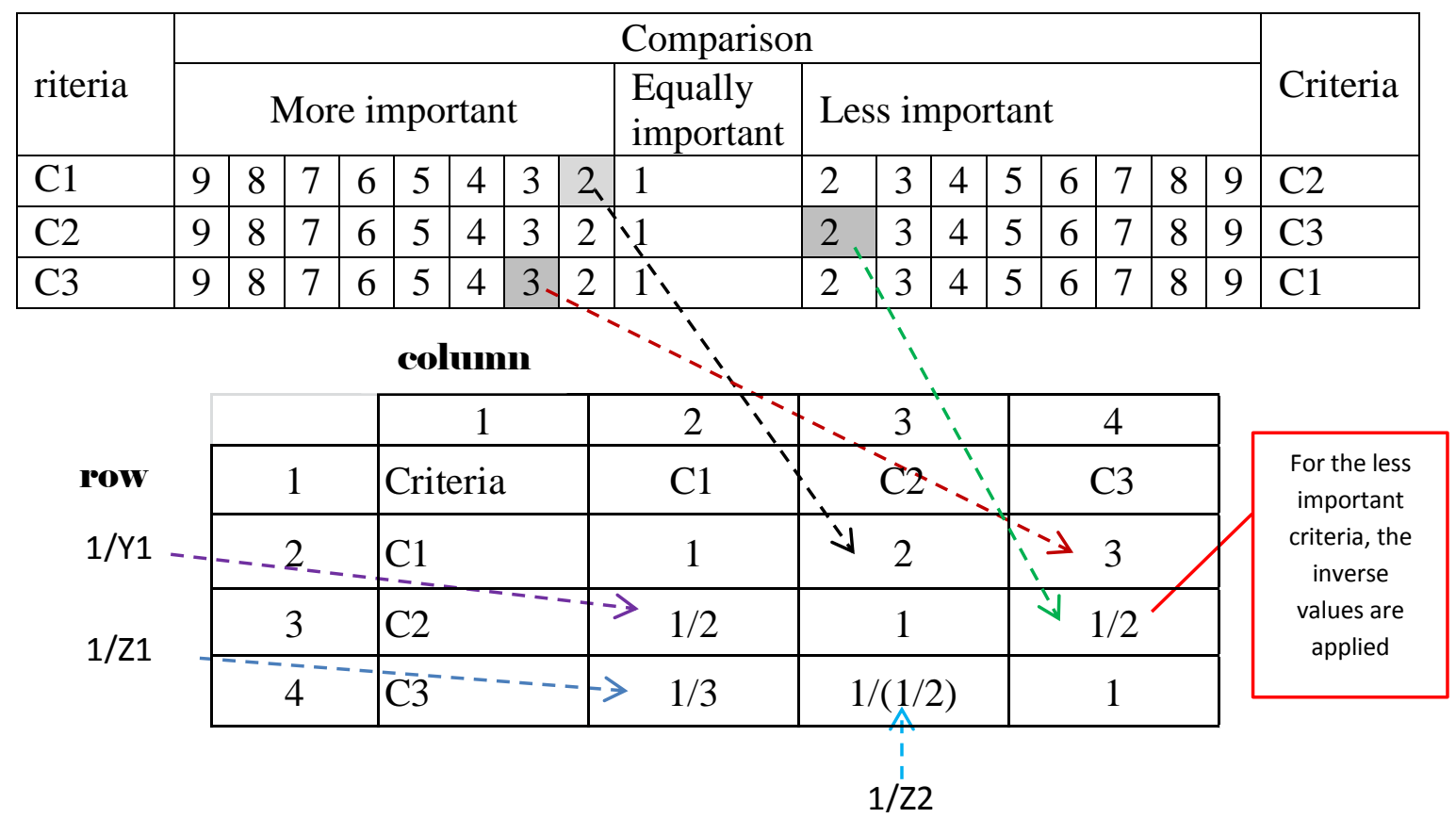

Table 1 explains the formation of criteria $\mathrm{C} 1, \mathrm{C} 2$, and $\mathrm{C} 3$ against each other. There are two parts of the matrix. The first is the upper of 1 diagonal and the lower (pairwise) 1 diagonal. There are two roles to fill the (upper) right side of the 1 diagonal. The first is that we put the same value as in the comparison table if the values belong to the more important side. Secondly, if the values belong to the less important side then we fill the reciprocal value into the matrix. The next step is to fill the pairwise (lower 1 diagonal) by using the formula: if a_ij is the value of row I and column $\mathrm{j}$ than the value of a_ij equal to $1 / a_{-} j$ i. For the ten criteria, we get the comparison pairwise matrix as shown in Table 2 below.

Table 2. Pairwise comparison matrix degree 10 (ten)

\begin{tabular}{|c|c|c|c|c|c|c|c|c|c|c|}
\hline Criteria & C1 & C2 & C3 & C4 & C5 & C6 & C7 & C8 & C9 & C10 \\
\hline C1 & 1 & 2 & 2 & 4 & 3 & 2 & 3 & 2 & 2 & 4 \\
\hline C2 & 0.50 & 1 & 1 & 3 & 2 & 1 & 2 & 3 & 3 & 3 \\
\hline C3 & 0.50 & 1.00 & 1 & 3 & 2 & 1 & 2 & 3 & 2 & 1 \\
\hline C4 & 0.25 & 0.33 & 0.33 & 1 & 0.5 & 0.33 & 2 & 0.5 & 0.33 & 2 \\
\hline C5 & 0.33 & 0.50 & 0.50 & 2.00 & 1 & 0.5 & 1 & 2 & 2 & 2 \\
\hline C6 & 0.50 & 1.00 & 1.00 & 3.03 & 2.00 & 1 & 3 & 2 & 1 & 2 \\
\hline C7 & 0.33 & 0.50 & 0.50 & 0.50 & 1.00 & 0.33 & 1 & 0.5 & 0.33 & 2 \\
\hline C8 & 0.50 & 0.33 & 0.33 & 2.00 & 0.50 & 0.50 & 2.00 & 1 & 1 & 2 \\
\hline C9 & 0.50 & 0.33 & 0.50 & 3.03 & 0.50 & 1.00 & 3.03 & 1.00 & 1 & 2 \\
\hline C10 & 0.25 & 0.33 & 1.00 & 0.50 & 0.50 & 0.50 & 0.5 & 0.5 & 0.5 & 1 \\
\hline Total & $\mathbf{4 . 6 7}$ & $\mathbf{7 . 3 3}$ & $\mathbf{8 . 1 7}$ & $\mathbf{2 2 . 0 6}$ & $\mathbf{1 3 . 0 0}$ & $\mathbf{8 . 1 6}$ & $\mathbf{1 9 . 5 3}$ & $\mathbf{1 5 . 5 0}$ & $\mathbf{1 3 . 1 6}$ & $\mathbf{2 1 . 0 0}$ \\
\hline
\end{tabular}




\section{Step 2: Matrix Normalization}

Each column has to be added to get the total value that will be utilized to divide the value of each column to generate normalize scores. As a result, the total of the normalized score equal to one since it was divided by the total of each column (Table 3 ). Find the total of each row and calculate the average of the rows.

Table 3 Normalize matrix

\begin{tabular}{|c|c|c|c|c|c|c|c|c|c|c|c|c|}
\hline Criteria & C1 & C2 & C3 & C4 & C5 & C6 & C7 & C8 & C9 & C10 & Total & Average \\
\hline C1 & 0.21 & 0.27 & 0.24 & 0.18 & 0.23 & 0.24 & 0.15 & 0.13 & 0.15 & 0.19 & 2.01 & 0.20 \\
\hline C2 & 0.11 & 0.14 & 0.12 & 0.14 & 0.15 & 0.12 & 0.10 & 0.19 & 0.23 & 0.14 & 1.45 & 0.14 \\
\hline C3 & 0.11 & 0.14 & 0.12 & 0.14 & 0.15 & 0.12 & 0.10 & 0.19 & 0.15 & 0.05 & 1.27 & 0.13 \\
\hline C4 & 0.05 & 0.05 & 0.04 & 0.05 & 0.04 & 0.04 & 0.10 & 0.03 & 0.03 & 0.10 & 0.52 & 0.05 \\
\hline C5 & 0.07 & 0.07 & 0.06 & 0.09 & 0.08 & 0.06 & 0.05 & 0.13 & 0.15 & 0.10 & 0.86 & 0.09 \\
\hline C6 & 0.11 & 0.14 & 0.12 & 0.14 & 0.15 & 0.12 & 0.15 & 0.13 & 0.08 & 0.10 & 1.23 & 0.12 \\
\hline C7 & 0.07 & 0.07 & 0.06 & 0.02 & 0.08 & 0.04 & 0.05 & 0.03 & 0.03 & 0.10 & 0.55 & 0.05 \\
\hline C8 & 0.11 & 0.05 & 0.04 & 0.09 & 0.04 & 0.06 & 0.10 & 0.06 & 0.08 & 0.10 & 0.72 & 0.07 \\
\hline C9 & 0.11 & 0.05 & 0.06 & 0.14 & 0.04 & 0.12 & 0.16 & 0.06 & 0.08 & 0.10 & 0.90 & 0.09 \\
\hline C10 & 0.05 & 0.05 & 0.12 & 0.02 & 0.04 & 0.06 & 0.03 & 0.03 & 0.04 & 0.05 & 0.49 & 0.05 \\
\hline Total & $\mathbf{1 . 0}$ & $\mathbf{1 . 0}$ & $\mathbf{1 . 0}$ & $\mathbf{1 . 0}$ & $\mathbf{1 . 0}$ & $\mathbf{1 . 0}$ & $\mathbf{1 . 0}$ & $\mathbf{1 . 0}$ & $\mathbf{1 . 0}$ & $\mathbf{1 . 0}$ & & 1.00 \\
\hline
\end{tabular}

\section{Step 2: Analysis of consistency}

The average value of Table 3 will be jointed to the comparison pairwise matrix of Table 2 and then the calculation of consistency index is ready as a basis to calculate Consistency Ratio (CR). To get the Consistency Index (CI) this paper use

$$
C R=\frac{C I}{R I}
$$

The random index (RI) with $\mathrm{n}$ order of matrix in this paper is provided in the table of Saaty (1980) as follows:
Excel's matrix multiplication function (MMULT()). Calculate the consistency ratio, $\mathrm{CR}$, as follows:

$$
C I=\frac{\text { Average } M M U L T-n}{n-1}
$$

therefore

\begin{tabular}{|l|c|c|c|c|c|c|c|c|c|c|}
\hline $\mathrm{n}$ & 1 & 2 & 3 & 4 & 5 & 6 & 7 & 8 & 9 & 10 \\
\hline $\mathrm{RI}$ & 0 & 0 & 0.58 & 0.9 & 1.12 & 1.24 & 1.32 & 1.41 & 1.45 & 1.49 \\
\hline
\end{tabular}

Since the matrix is in order 10 then the RI value is 1.49 . The consistency ratio must not exceed 0.10 . The $\mathrm{CR}$ more than 0.10 means the calculation is not consistent and needs to be evaluated for further refinement.
Based on calculation in Table 4 the $\mathrm{CR}$ is 0.05 which is far less than 0.10 indicating that the judgment of this simulation calculation is consistent 
Table 4 Consistency Ratio

\begin{tabular}{|c|c|c|c|c|c|c|c|c|c|c|r|r|}
\hline Kriteria & C1 & C2 & C3 & C4 & C5 & C6 & C7 & C8 & C9 & C10 & Average & MMULT \\
\hline C1 & 1 & 2 & 2 & 4 & 3 & 2 & 3 & 2 & 2 & 4 & 0.20 & 10.63 \\
\hline C2 & 0.50 & 1 & 1 & 3 & 2 & 1 & 2 & 3 & 3 & 3 & 0.14 & 10.84 \\
\hline C3 & 0.50 & 1.00 & 1 & 3 & 2 & 1 & 2 & 3 & 2 & 1 & 0.13 & 10.82 \\
\hline C4 & 0.25 & 0.33 & 0.33 & 1 & 0.5 & 0.33 & 2 & 0.5 & 0.33 & 2 & 0.05 & 10.57 \\
\hline C5 & 0.33 & 0.50 & 0.50 & 2.00 & 1 & 0.5 & 1 & 2 & 2 & 2 & 0.09 & 10.86 \\
\hline C6 & 0.50 & 1.00 & 1.00 & 3.03 & 2.00 & 1 & 3 & 2 & 1 & 2 & 0.12 & 10.70 \\
\hline C7 & 0.33 & 0.50 & 0.50 & 0.50 & 1.00 & 0.33 & 1 & 0.5 & 0.33 & 2 & 0.05 & 10.53 \\
\hline C8 & 0.50 & 0.33 & 0.33 & 2.00 & 0.50 & 0.50 & 2.00 & 1 & 1 & 2 & 0.07 & 10.65 \\
\hline C9 & 0.50 & 0.33 & 0.50 & 3.03 & 0.50 & 1.00 & 3.03 & 1.00 & 1 & 2 & 0.09 & 10.64 \\
\hline C10 & 0.25 & 0.33 & 1.00 & 0.50 & 0.50 & 0.50 & 0.5 & 0.5 & 0.5 & 1 & 0.05 & 10.54 \\
\hline & & & & & & & & & & Cl & $\mathbf{0 . 0 8}$ \\
\hline & & & & & & & & & & $\mathbf{R I}$ & $\mathbf{1 . 4 9}$ \\
\hline
\end{tabular}

The next step is to make valuation to police cadets by using the criteria $(\mathrm{C} 1-\mathrm{C} 10)$. For simplicity purposes, the paper chooses five police cadets and names them as CT1, CT2, CT3, CT4, and CT5. In the real recruitment process, it will involve hundred, thousand or hundred thousand applicants in which with the modern computer system the calculation is not a big issue. The next step is the decision matrix. The judges make their valuation by using Table 5 . The assessment ranges from 1 to 10 depending on how the judges assess the police cadets' performance among the ten criteria. The judgment results are summarized in Table 5. From the table, we can recognize the highest mark of the criteria in its related column. Similar to previous calculation, the normalization matrix (Table 6) will be created by dividing each record using the highest value of the related criteria (column, color mark)

Table 5 Highest mark of the criteria

\begin{tabular}{|l|c|c|c|c|c|c|c|c|c|c|c|}
\hline CT/C & C1 & C2 & C3 & C4 & C5 & C6 & C7 & C8 & C9 & C10 & Total \\
\hline CT1 & 4 & 7 & 3 & 5 & 7 & 2 & 3 & 6 & 4 & 3 & 44 \\
\hline CT2 & 3 & 8 & 4 & 3 & 5 & 6 & 3 & 5 & 4 & 7 & 48 \\
\hline CT3 & 6 & 5 & 4 & 6 & 6 & 3 & 2 & 6 & 2 & 5 & 45 \\
\hline CT4 & 5 & 3 & 2 & 7 & 5 & 4 & 5 & 7 & 3 & 3 & 44 \\
\hline CT5 & 2 & 5 & 6 & 5 & 4 & 5 & 4 & 6 & 6 & 6 & 49 \\
\hline
\end{tabular}

Therefore the normalization matrix become as follows: 
Table 6. Normalization matrix.

\begin{tabular}{|c|c|c|c|c|c|c|c|c|c|c|}
\hline CT/C & C1 & C2 & C3 & C4 & C5 & C6 & C7 & C8 & C9 & C10 \\
\hline CT1 & 0.67 & 1.00 & 0.50 & 0.71 & 1.00 & 0.33 & 0.60 & 0.86 & 0.67 & 0.43 \\
\hline CT2 & 0.50 & 1.14 & 0.67 & 0.43 & 0.71 & 1.00 & 0.60 & 0.71 & 0.67 & 1.00 \\
\hline CT3 & 1.00 & 0.71 & 0.67 & 0.86 & 0.86 & 0.50 & 0.40 & 0.86 & 0.33 & 0.71 \\
\hline CT4 & 0.83 & 0.43 & 0.33 & 1.00 & 0.71 & 0.67 & 1.00 & 1.00 & 0.50 & 0.43 \\
\hline CT5 & 0.33 & 0.71 & 1.00 & 0.71 & 0.57 & 0.83 & 0.80 & 0.86 & 1.00 & 0.86 \\
\hline
\end{tabular}

The normalization matrix will be multiplied by the result of step 3 which is the average of the criteria. Table 7 describes the multiplication results.

Table 7. Final rank by SAW method

\begin{tabular}{|c|c|c|c|c|c|c|c|c|c|c|c|c|}
\hline CT/C & C1 & C2 & C3 & C4 & C5 & C6 & C7 & C8 & C9 & C10 & Total & Total X 100 \\
\hline CT1 & 0.13 & 0.14 & 0.06 & 0.04 & 0.09 & 0.04 & 0.03 & 0.06 & 0.06 & 0.02 & $\mathbf{0 . 6 8}$ & $\mathbf{6 8 . 2 0}$ \\
\hline CT2 & 0.10 & 0.17 & 0.08 & 0.02 & 0.06 & 0.12 & 0.03 & 0.05 & 0.06 & 0.05 & $\mathbf{0 . 7 5}$ & $\mathbf{7 5 . 0 8}$ \\
\hline CT3 & 0.20 & 0.10 & 0.08 & 0.04 & 0.07 & 0.06 & 0.02 & 0.06 & 0.03 & 0.03 & $\mathbf{0 . 7 2}$ & $\mathbf{7 1 . 7 8}$ \\
\hline CT4 & 0.17 & 0.06 & 0.04 & 0.05 & 0.06 & 0.08 & 0.05 & 0.07 & 0.05 & 0.02 & $\mathbf{0 . 6 6}$ & $\mathbf{6 6 . 0 3}$ \\
\hline CT5 & 0.07 & 0.10 & 0.13 & 0.04 & 0.05 & 0.10 & 0.04 & 0.06 & 0.09 & 0.04 & $\mathbf{0 . 7 2}$ & $\mathbf{7 2 . 4 1}$ \\
\hline
\end{tabular}

We are ready to compare the rank based on the judge's total mark and the SAW's total value (Table 8). It is clear that the judges have two police cadets with a similar rank that is CT1 and CT4. By calculating the value of the SAW method these double ranks can be avoided and all value is different in their weighting result of its 10 criteria.

Table 8. Final rank

\begin{tabular}{|c|c|c|c|c|c|}
\hline Cadets & SAW & Rank & Cadets & Judge & Rank \\
\hline CT1 & 68.20 & 4 & CT1 & 44 & 4 \\
\hline CT2 & 75.08 & 1 & CT2 & 48 & 2 \\
\hline CT3 & 71.78 & 3 & CT3 & 45 & 3 \\
\hline CT4 & 66.03 & 5 & CT4 & 44 & 4 \\
\hline CT5 & 72.41 & 2 & CT5 & 49 & 1 \\
\hline
\end{tabular}

The survey response rate is more than 90 percent which is 10 percent higher than the ideal requirement (Finchan, 2008). Having has no issues with nonresponse bias, the survey findings support that the recruitment process in Akpol has established the basic requirement of good governance which is transparency and accountability. The police candidates and police cadets perceive that the recruitment process was fair and 
transparent but some of them also argued that improvement might open up the possibilities to better results.

\section{CONCLUSION}

Less pressure in the recruitment process and the different weight to academic tests are among those prospects of advancement. The depth interview also reveals that no case of corruption, collusion, and nepotism was found in the 2012 Akpol recruitment process. Overall the results strengthen the finding of the Indonesian Police Headquarter (Mabes Polri) survey in which found that recruitment of the police cadet in 2012 shows satisfactory outcomes (Mabes Polri, 2012).

There are some rooms for further development of the recruitment procedures to make sure that Polri hires the best human

\section{REFERENCES}

Afshari, A., Majid Mojahed, and Rosnah Mohd Yusuff (2010)," Simple Additive Weighting Approach to Personel Selection Problem, " International Journal of Innovation, Management and Technology, Vol 1, No 5, December 2010

Finchan, J.E., (2008) Response Rates and Responsiveness for Surveys standards and the Journal, American Journal of Pharmaceutical Education 2008; 72 (2) Article 43.

Lembaga Administrasi Negara, 2001, Akuntabilitas dan Good Governance, Jakarta.

Mabes Polri (2012), "Laporan Hasil Survey Kepuasan Pelanggan 2012”, Bidang SDM, Sukabumi Bandung 2012 resources as a future leader. Mabes can create a system of supervision in such a way that automatic self-check is applied to the recruitment steps to avoid any illegal and unlawful actions either from internal Polri institution or police candidates or cadets. There are practical issues and inquiries of grading and ranking for some applicants who need clear information on the cut-off point. How someone can be at a certain grade and therefore be in particular rank among other applicants are still dubious for some applicants. As a complementary method that meets scientific methodology and practice requirements, simple additive weighting may give some light for the grading and ranking trivial issues.

OSCE (Organisation for Security and Cooperation in Europe), (2008), Good Practices in Building Police-Public Partnerships, Office of the SecretaryGeneral OSCE Secretariat Wallnerstrasse 6, A-1010 Vienna, Austria

PEAC (1998) Police for the Future: Review of recruitment and selection for the Queensland Police Service, Brisbane: Police Education Advisory Council

Pynes, J., and Bernardin, H.J., (1992) EntryLevel Police Selection: The Assessment, Journal of Criminal Justice Vol. 20, pp. 41-52

Saaty, T.L. (1980). The analytic hierarchy process. McGraw-Hill, New York.

Saaty, T.L., Vargas, L.G. (1991). Prediction, Projection, and Forecasting.Kluwer academic publishers, Dordrecht, $251 \mathrm{pp}$.

Sheng Y.K., 2009, What is Good Governance?, UNESCAP Technical 
Committee of the International Organization of Securities

Commissions, 2011, Regulatory Issues Raised by the Impact of Technological Changes on Market Integrity and Efficiency, Consultation Report, July

Trojanowicz, Robert/Bucqueroux, Bonnie (1998), Community Policing: How to get started, second edition, Cincinnati 1998.

Walsh, D.P.J., and Conway, V., (2011) Police governance and accountability: an overview of current issues. Crime, Law and Social Change, Springer Verlag, 2011, 55 (2-3), pp.61-86. 